\title{
Forecasting of Coconut Production in India: An approach with ARIMA, ARIMAx and Combined Forecast Techniques
}

\author{
Lakshmi Narsimhaiah*, P.K. Sahu, Kanchan Sinha, Sh Herojit Singh, \\ Soumik Dey and Pramit Pandit \\ Department of Agricultural Statistics, Bidhan Chandra Krishi Vishwavidalaya, Mohanpur, \\ Nadia, West Bengal-741252, India \\ *Corresponding author
}

\section{A B S T R A C T}

Keywords

Coconut, Modeling, Forecasting,

ARIMA, ARIMAx, Combined forecast

Article Info

Accepted:

12 October 2019

Available Online:

10 November 2019
Coconut is an important plantation crop which India holds third position in production. Coconut has the never ending list of uses also is facing numerous hurdles adding pressure to the mere survival of the sector. With increasing human population forecasting methods can help estimate many such future aspects. ARIMA, ARIMAx and Combined forecast techniques used to model and forecast the production of coconut until 2020 using time series data for a period of 1949 to 2015 . For India as a whole the best fitted models ARIMA (1,1,2), ARIMAx $(1,1,0)$ and the Combined forecast techniques projected coconut production to be 23396.122, 33013.792, 28204.957 Million nuts respectively. It is found that combined forecasting performed better compared with ARIMA and ARIMAx in all most all cases considering the criteria of R2, RMSE, MAE and MAPE. Among the three methods of modeling and forecasting ARIMAx models outperform ARIMA models and combined forecasting method yields better modeling and forecasting accuracy.

\section{Introduction}

India is the third largest producer of coconut. Kerala, Tamil Nadu, Karnataka, Andhra Pradesh and West Bengal are the major states which are producing (More than 92\% together) coconuts in India. Coconut sector is facing numerous hurdles like vagaries of weather coupled with climatic change, lack of investment, quality cultivars, mostly confined to small holdings, decrease in planting areas due to various reasons like rapid urbanization, labour migration, increased wages, nonavailability of quality inputs, risks confronted at the marketing sector like stiff competition from global players, trade agreements, tariff 
structure, government intervention, price transmission from the global markets, fluctuating currency, etc. add pressure to the mere survival of this sector not only in domestic sector but also in international sector. World population particularly the population of developing world is increasing at an alarming rate. To feed these ever increasing human populations remains a challenging task to the planners.

Planning for the future is a critical aspect of managing. The planners should have idea about the likely production scenario of the concerned crops. Forecasting methods can help estimate many such future aspects of any business operation and so also in agriculture. With advancement in science various statistical techniques has been evolved for future predictions of crop production. But sometimes it may not be feasible to develop a single model based on different types of data. In such a situation separate models based on different group of variables may be developed and forecasts obtained from these models may be combined to get a composite forecast and same is attempted here in the present study of area, production and productivity which in turn have a motto to foresee what could be the future behavior of coconut in India.

\section{Materials and Methods}

Depending upon the production performance of the major growing states for coconut and scrutinizing the data for each state, it was noticed that continuous and quality data were available for Kerala, Tamil Nadu, Karnataka, Andhra Pradesh and West Bengal (produces more than $92 \%$ together) of total Indian coconut production respective. State wise time series data on area, production and productivity of coconut and also state-wise NPK fertilizer consumption data for the period of 1949-2015 was collected from www.Indiastat.com and various issues of fertilizer statistics respectively. First data is scrutinized for the presence of any outliers using Grubbs' test. On rejection of outlier or replacement of extreme values if any by median, the data are subjected to test of randomness using turning point test. The most widely used descriptive measure of central tendency and dispersion like minimum, maximum, arithmetic mean, standard deviation, skewness, kurtosis along with simple and compound growth rates are used to explain each series.

Each time series is later subjected by two important stationarity test-ADF (Augmented Dickey Fuller) and KPSS (KwiatkowskiPhillips-Schmidt-Shin) test. When the data are non-stationary, to be brought into stationary by the methods like differencing.

\section{Box-Jenkins [Auto Regressive Integrated Moving Average (ARIMA)] model}

Box-Jenkins time series models written as ARIMA (p, d, q) was first popularized by Box, G.E.P and Jenkins, G.M (1976). This model take care of three types of processes, viz., auto regressive of order $\mathrm{p}$; differencing to make a series stationary of degree $d$ and moving average of order $\mathrm{q}$ as this method applies only to a stationary time series data.

\section{Autoregressive model}

The notation AR (p) refers to the autoregressive model of order $p$. The $\operatorname{AR}(p)$ model is written

$$
X_{t}=c+\sum_{i=1}^{P} \rho_{i} X_{t}+\varepsilon_{t}
$$

Where $\rho_{1}, \rho_{2} \ldots . \rho_{p}$ are the parameters of the model, $c$ is a constant and $\varepsilon_{t}$ is white noise. Sometimes the constant term is avoided. 


\section{Moving average model}

The notation MA $(q)$ refers to the moving average series of order $q$ :

$$
X_{t}=\mu+\varepsilon_{t}+\sum_{i=1}^{q} \theta_{i} \varepsilon_{t-i}
$$

Where the $\theta_{1}, \ldots, \theta_{q}$ are the parameters of the model, $\mu$ is the expectation of $X_{t}$ (often assumed to equal 0 ), and the $\varepsilon_{t}, \varepsilon_{t-1}$ are error term.

\section{ARIMAx technique for forecasting of coconut production and yield}

As present performance in production of any crop not only depends on its past performances but also on other supporting input factors, these were also included in the model; as such ARIMAx models were also conceived. ARIMAx model is a generalization of ARIMA model and is capable of incorporating external input variable(s) (X's). ARIMAx is carried for the production and productivity data of the crops considered. Here in the current study annual total nitrogen, total phosphorus and total potassium consumption by states and India as a whole was considered as the external input. Initially, considered input variable(s) (X's) are modeled individually to get the estimated values for the observed data points and forecasted based on the best fitted ARIMA models in respective series. In the second step, these forecasted values are used as auxiliary/independent variable in the ARIMAx models of the production and productivity series. All developed ARIMAx models are compared for error diagnostic criteria i.e. RMSE, MAE, MAPE and value of $R^{2}$. The method which provides lower value of error diagnostic criteria and maximum value of $R^{2}$ is selected as best fitted model for coconut production and productivity forecasting.

\section{Composite forecast}

To improve forecasting accuracy, combine forecasts derived from methods that differ substantially and draw from different sources of information. Use formal procedures to combine forecasts: An equal-weights rule offers a reasonable starting point, and a trimmed mean is desirable if you combine forecasts resulting from five or more methods. Combining forecasts is especially useful when you are uncertain about the situation, uncertain about which method is most accurate, and when you want to avoid large errors. Compared with errors of the typical individual forecast, combining reduces errors. Combining should be done mechanically and the procedure should be fully described. Equal weighting is appealing because it is simple and easy to describe and the present investigation used it.

ARIMA models, ARIMAx models and combine forecast are selected as best fit models/ or evaluated based on the criteria of $\mathrm{R}^{2}$, RMSE, MAE and MAPE.

\section{Results and Discussion}

From the table 1, one can find that, during the period under study average production for India under coconut was 9161.757 million nuts, with maximum production recorded 23351.220 million nuts (during the year 2011), while the minimum production was 3147.700 million nuts (during the year 1949). Increase in production of nuts in India is being reflected through simple as well as compound growth rates of $11.848 \%$ and $3.902 \%$ respectively during the period under study. Lepto kurtic and positive skewness clearly indicate that production of coconut showed maximum shift or improvement at early stages. All the states considered showed positively skewed production pattern which clearly indicates that coconut production showed steady changes at early stage 
commesurating with the changes in pattern of area. This finding of positive growth rates in production of coconut is not in conformity with the findings of Krishnan et al., (1991) who showed negative growth rates production of four major crops including coconut in Kerala, though for a short study period of 1970-71 to 1986-87. Excepting Karnataka, all other states recorded platy kurtic nature of coconut production.

Among the states considered maximum compound growth rate found in West Bengal with 5.691 per cent (accompanied with 31.035 $\%$ SGR) followed by Karnataka and Tamil Nadu with 5.463 and 5.214 per cent respectively. Kerala, even with highest average production i.e, 4251.153 million nuts under period considered showed lowest compound growth of 2.688 per cent; a clear cut reflection of change in area under coconut in Kerala. The annual time series of coconut production for Karnataka noticed a gradual increase over the first half of the study period and later noticed rapid increase in recent years.

Test of outliers and randomness for production of coconut

From table 2 the results of both the test of randomness and that of outlier are presented for coconut. A few outliers are detected e.g. in case production of Karnataka, Kerala, Tamil Nadu and India as a whole indicating significant deviation from the aggregate pattern and thereby differential potentialities of growth. These outliers were of high values and kept untouched for the analysis since they were found in recent time and acceptable. From the test of randomness one can see that production of coconut in case of all states considered and whole India have changed with trend.

\section{Modeling and forecasting of coconut production}

From stationarity test for the production series of coconut, it is observed that, all the data series are non-stationary in nature (Table 3). The non-stationary data series are made stationary by first order differencing except the case of Kerala where second order differencing is performed to achieve the stationarity. After achieving stationarity, various ARIMA models are tried for each series and only best models among the competitive model for each series is selected based on minimum value of RMSE, MAPE, MAE and maximum value of $\mathrm{R}^{2}$ and presented in table 4. From the table it is clear that ARIMA (1,1,2), ARIMA(1,1,1), ARIMA $(4,2,0)$, ARIMA $(1,1,1)$ ARIMA $(1,1,1)$ and ARIMA $(1,1,2)$ are found to be best ARIMA model for modeling coconut production in Andhra Pradesh, Karnataka, Kerala, West Bengal, Tamil Nadu and India respectively.

In ARIMAx, first all the independent variables are modeled and forecasted up to 2020 using ARIMA technique. Then these forecasted values are used as independent variables in the ARIMAx model. As in case of ARIMA, here also best ARIMAx model has been selected based on minimum value of RMSE, MAPE, MAE and maximum value of $R^{2}$ and presented in table 4. It can be noted that $\operatorname{ARIMAx}(0,1,1)$ for Andhra Pradesh and Kerala; $\operatorname{ARIMAx}(3,2,0)$ for West Bengal and Tamil $\mathrm{Nadu}$; $\operatorname{ARIMAx}(1,1,2)$ for Karnataka and $\operatorname{ARIMAx}(1,1,0)$ for India respectively are the best ARIMAx models among the various competitive ARIMAx models for modeling coconut production. The results of Ljung-Box test of residuals also reject the presence of significant auto correlation in the residuals of the best fitted ARIMA and ARIMAx model. 
Table.1 Per se performance of coconut production (in Million Nuts) in major states of India during 1949-2015

\begin{tabular}{|c|c|c|c|c|c|c|}
\hline Particulars & $\begin{array}{c}\text { Andhra } \\
\text { Pradesh }\end{array}$ & Karnataka & Kerala & $\begin{array}{c}\text { West } \\
\text { Bengal }\end{array}$ & $\begin{array}{c}\text { Tamil } \\
\text { Nadu }\end{array}$ & India \\
\hline Minimum & 157.000 & 339.400 & 1920.200 & 22.000 & 409.600 & 3147.700 \\
\hline Maximum & 1477.989 & 6058.860 & 7429.390 & 395.280 & 6917.460 & 23351.220 \\
\hline Average & 597.136 & 1296.611 & 4251.153 & 163.595 & 2251.715 & 9161.757 \\
\hline Skewness & 0.585 & 2.501 & 0.419 & 0.227 & 1.056 & 1.048 \\
\hline Kurtosis & -1.321 & 5.736 & -1.020 & -1.720 & -0.066 & 0.144 \\
\hline SE of & 56.433 & 158.695 & 162.095 & 18.029 & 237.814 & 657.885 \\
Mean & 7.006 & 27.583 & 5.626 & 31.035 & 24.230 & 11.848 \\
\hline SGR (\%) & 3.026 & 5.463 & 2.688 & 5.691 & 5.214 & 3.902 \\
\hline CGR (\%) & & & & & \\
\hline
\end{tabular}

Table.2 Test of outliers and randomness for production of coconut

\begin{tabular}{|c|c|c|c|c|c|c|}
\hline $\begin{array}{c}\text { Test of } \\
\text { randomness }\end{array}$ & $\begin{array}{c}\text { Andhra } \\
\text { Pradesh }\end{array}$ & Karnataka & Kerala & $\begin{array}{c}\text { West } \\
\text { Bengal }\end{array}$ & $\begin{array}{c}\text { Tamil } \\
\text { Nadu }\end{array}$ & India \\
\hline $\begin{array}{c}\text { No. of } \\
\text { Observation }\end{array}$ & 67 & 67 & 67 & 67 & 67 & 67 \\
\hline No. of Point (p) & 26 & 19 & 29 & 15 & 30 & 34 \\
\hline $\mathbf{E}(\mathbf{P})$ & 44.667 & 44.667 & 44.667 & 44.667 & 44.667 & 44.667 \\
\hline $\mathbf{V ( P )}$ & 11.589 & 11.589 & 11.589 & 11.589 & 11.589 & 11.589 \\
\hline $\boldsymbol{\tau}_{\text {cal }}$ & -5.483 & -7.540 & -4.602 & -8.715 & -4.308 & -3.133 \\
\hline Inference & Trend & Trend & Trend & Trend & Trend & Trend \\
\hline Outliers Test & No & Yes & Yes & No & Yes & Yes \\
\hline
\end{tabular}

Table.3 Test of stationarity for production of coconut in India for observed data

\begin{tabular}{|c|c|c|c|c|c|c|}
\hline State & $\begin{array}{c}\text { ADF } \\
\text { i. }\end{array}$ & P-value & Conclusion & $\begin{array}{c}\text { KPSS } \\
\text { P-value }\end{array}$ & Conclusion \\
\hline Andhra Pradesh & -2.658 & 0.246 & Non Stationary & 2.356 & $<0.001$ & Non Stationary \\
\hline Karnataka & -1.710 & 0.717 & Non Stationary & 1.515 & $<0.001$ & Non Stationary \\
\hline Kerala & -1.819 & 0.667 & Non Stationary & 2.240 & $<0.001$ & Non Stationary \\
\hline West Bengal & -1.463 & 0.808 & Non Stationary & 2.485 & $<0.001$ & Non Stationary \\
\hline Tamil Nadu & -1.975 & 0.588 & Non Stationary & 2.288 & $<0.001$ & Non Stationary \\
\hline India & -1.313 & 0.848 & Non Stationary & 2.338 & $<0.001$ & Non Stationary \\
\hline
\end{tabular}


Table.4 ARIMA, ARIMAx and combined model for production of coconut in India

\begin{tabular}{|c|c|c|c|c|c|c|c|}
\hline \multirow[t]{2}{*}{ State } & \multirow[t]{2}{*}{ Models } & \multicolumn{4}{|c|}{ Model selection criteria } & \multicolumn{2}{|c|}{$\begin{array}{l}\text { Ljung-Box test } \\
\text { for residuals }\end{array}$} \\
\hline & & $\mathbf{R}^{2}$ & RMSE & MAPE & MAE & $\chi^{2}$ & P Value \\
\hline \multicolumn{8}{|c|}{ ARIMA Models } \\
\hline Andhra Pradesh & $(1,1,2)$ & 0.906 & 147.385 & 12.338 & 80.143 & 14.438 & 0.493 \\
\hline Karnataka & $(1,1,1)$ & 0.763 & 532.954 & 7.185 & 148.534 & 9.872 & 0.873 \\
\hline Kerala & $(4,2,0)$ & 0.898 & 387.595 & 5.701 & 260.313 & 7.493 & 0.914 \\
\hline West Bengal & $(1,1,1)$ & 0.971 & 24.067 & 5.767 & 11.968 & 19.433 & 0.247 \\
\hline Tamil Nadu & $(1,1,1)$ & 0.936 & 436.806 & 9.831 & 274.786 & 11.287 & 0.791 \\
\hline India & $(1,1,2)$ & 0.939 & 1188.739 & 5.886 & 669.749 & 11.804 & 0.694 \\
\hline \multicolumn{8}{|c|}{ ARIMAx Models } \\
\hline Andhra Pradesh & $(0,1,1)$ & 0.926 & 131.994 & 14.344 & 77.609 & 17.648 & 0.411 \\
\hline Karnataka & $(1,1,2)$ & 0.925 & 314.230 & 12.518 & 182.945 & 7.249 & 0.950 \\
\hline Kerala & $(0,1,1)$ & 0.911 & 362.844 & 5.675 & 257.063 & 12.355 & 0.778 \\
\hline West Bengal & $(3,2,0)$ & 0.968 & 26.248 & 7.253 & 13.539 & 14.402 & 0.495 \\
\hline Tamil Nadu & $(3,2,0)$ & 0.928 & 485.967 & 11.693 & 300.139 & 15.302 & 0.430 \\
\hline India & $(1,1,0)$ & 0.954 & 1036.952 & 6.189 & 677.078 & 12.958 & 0.739 \\
\hline \multicolumn{8}{|c|}{ ARIMA+ARIMAx } \\
\hline Andhra Pradesh & - & 0.926 & 128.010 & 12.528 & 70.965 & - & - \\
\hline Karnataka & - & 0.892 & 361.714 & 8.666 & 150.068 & - & - \\
\hline Kerala & - & 0.918 & 340.828 & 5.134 & 234.733 & - & - \\
\hline West Bengal & - & 0.972 & 23.552 & 6.250 & 12.216 & - & - \\
\hline Tamil Nadu & - & 0.937 & 429.076 & 10.557 & 276.155 & - & - \\
\hline India & - & 0.953 & 1022.757 & 5.738 & 640.688 & - & - \\
\hline
\end{tabular}


Fig.1 ACF and PACF graphs of residuals for the best fitted ARIMA models of production of coconut in India
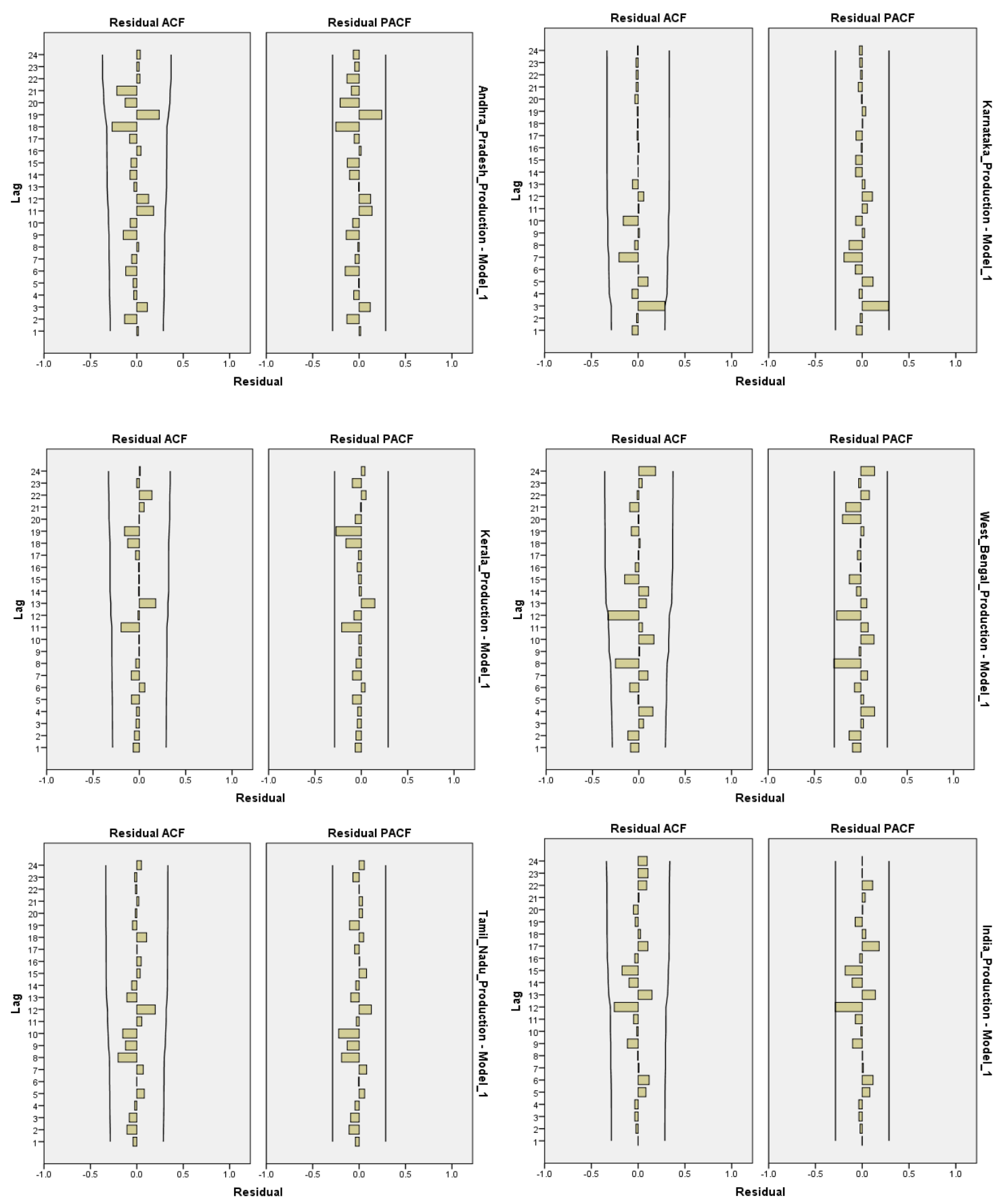
Fig.2 ACF and PACF graphs of residuals for the best fitted ARIMAx models of production of coconut in India
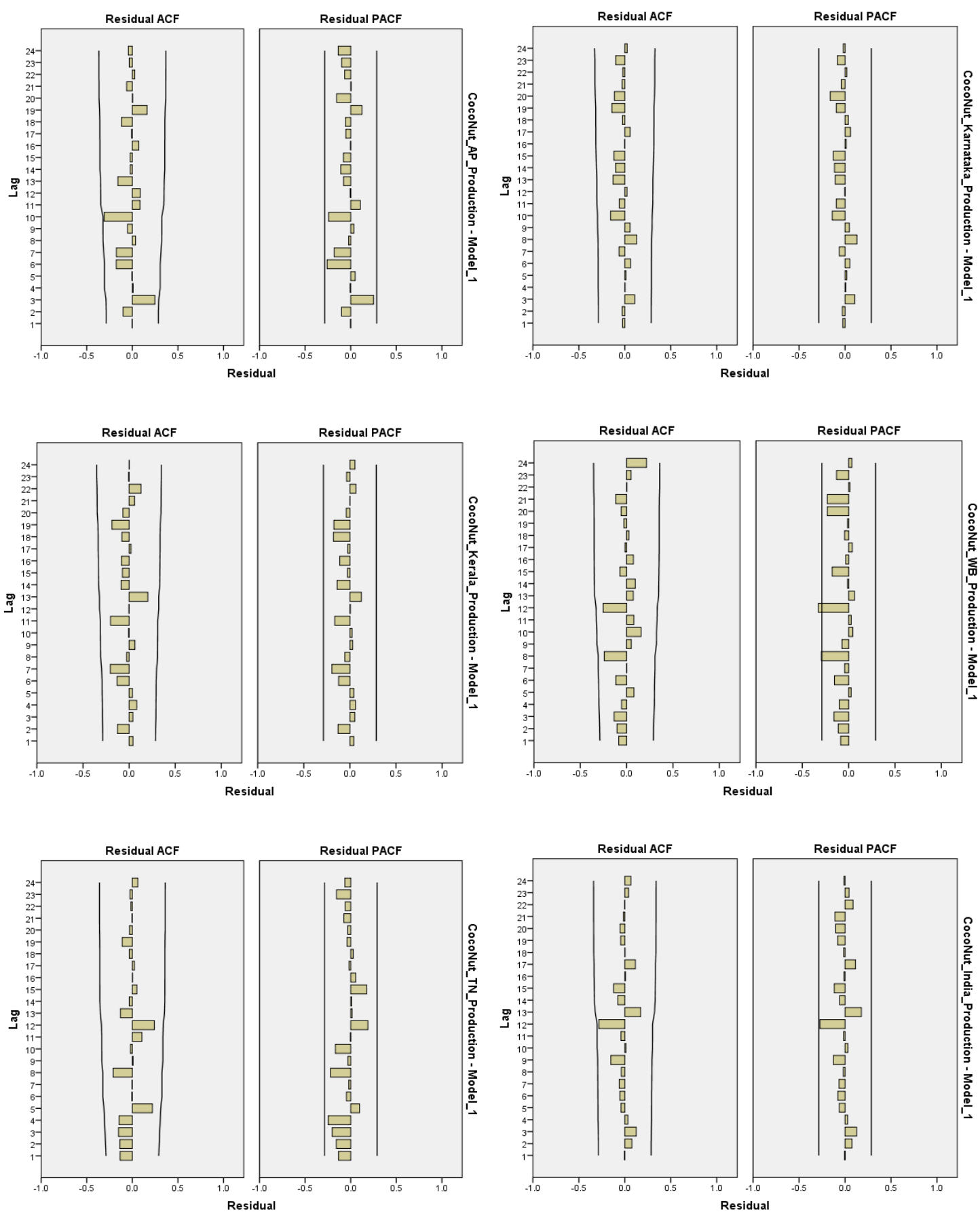
Table.5 Observed and forecasted production (in Million nuts) of coconut in India

\begin{tabular}{|c|c|c|c|c|c|c|c|c|c|c|c|c|}
\hline \multirow[t]{2}{*}{ State } & \multirow[t]{2}{*}{ Model } & \multicolumn{3}{|c|}{ Observed } & \multicolumn{3}{|c|}{ Predicted } & \multicolumn{5}{|c|}{ Forecasted } \\
\hline & & 2013 & 2014 & 2015 & 2013 & 2014 & 2015 & 2016 & 2017 & 2018 & 2019 & 2020 \\
\hline \multirow[t]{3}{*}{ Andhra Pradesh } & $\operatorname{ARIMA}(1,1,2)$ & \multirow[t]{3}{*}{1410.005} & \multirow[t]{3}{*}{1447.900} & \multirow[t]{3}{*}{1427.745} & 1583.412 & 1526.393 & 1496.881 & 1461.755 & 1472.996 & 1500.674 & 1540.913 & 1590.656 \\
\hline & $\operatorname{ARIMAx}(0,1,1)$ & & & & 1458.761 & 1387.487 & 1501.751 & 1627.853 & 1841.932 & 2053.902 & 2284.651 & 2583.720 \\
\hline & Combined & & & & 1521.087 & 1456.940 & 1499.316 & 1544.804 & 1657.464 & 1777.288 & 1912.782 & 2087.188 \\
\hline \multirow[t]{3}{*}{ Karnataka } & $\operatorname{ARIMA}(1,1,1)$ & \multirow[t]{3}{*}{5041.150} & \multirow[t]{3}{*}{5141.150} & \multirow[t]{3}{*}{5128.840} & 5162.665 & 5715.289 & 4683.520 & 5752.955 & 5476.976 & 5826.980 & 5748.332 & 5968.878 \\
\hline & $\operatorname{ARIMAx}(1,1,2)$ & & & & 5558.918 & 5452.224 & 5658.067 & 5874.485 & 5966.541 & 6219.989 & 6248.045 & 6290.812 \\
\hline & Combined & & & & 5360.792 & 5583.757 & 5170.794 & 5813.720 & 5721.759 & 6023.485 & 5998.189 & 6129.845 \\
\hline \multirow[t]{3}{*}{ Kerala } & $\operatorname{ARIMA}(4,2,0)$ & \multirow[t]{3}{*}{5968.010} & \multirow[t]{3}{*}{5947.000} & \multirow[t]{3}{*}{7429.390} & 6012.609 & 6047.178 & 5841.009 & 7274.257 & 7352.468 & 7783.640 & 8261.794 & 8701.108 \\
\hline & $\operatorname{ARIMAx}(0,1,1)$ & & & & 6159.900 & 6126.398 & 6231.953 & 7107.499 & 7181.716 & 7241.266 & 7289.932 & 7325.968 \\
\hline & Combined & & & & 6086.255 & 6086.788 & 6036.481 & 7190.878 & 7267.092 & 7512.453 & 7775.863 & 8013.538 \\
\hline \multirow[t]{3}{*}{ West Bengal } & $\operatorname{ARIMA}(1,1,1)$ & \multirow[t]{3}{*}{370.830} & \multirow[t]{3}{*}{372.230} & \multirow[t]{3}{*}{373.580} & 372.002 & 373.346 & 374.579 & 375.776 & 377.881 & 379.899 & 381.832 & 383.685 \\
\hline & $\operatorname{ARIMAx}(3,2,0)$ & & & & 374.409 & 370.179 & 368.902 & 364.899 & 363.316 & 361.678 & 359.116 & 355.583 \\
\hline & Combined & & & & 373.206 & 371.763 & 371.741 & 370.338 & 370.599 & 370.789 & 370.474 & 369.634 \\
\hline \multirow[t]{3}{*}{ Tamil Nadu } & $\operatorname{ARIMA}(1,1,1)$ & \multirow[t]{3}{*}{6917.250} & \multirow[t]{3}{*}{6917.460} & \multirow[t]{3}{*}{6171.060} & 6968.132 & 6917.350 & 6917.475 & 6118.106 & 6114.246 & 6113.964 & 6113.944 & 6113.942 \\
\hline & $\operatorname{ARIMAx}(3,2,0)$ & & & & 7265.056 & 7027.874 & 6985.918 & 6014.082 & 5568.305 & 4933.696 & 3990.200 & 2957.986 \\
\hline & Combined & & & & 7116.594 & 6972.612 & 6951.697 & 6066.094 & 5841.276 & 5523.830 & 5052.072 & 4535.964 \\
\hline \multirow[t]{3}{*}{ India } & $\operatorname{ARIMA}(1,1,2)$ & \multirow[t]{3}{*}{21665.190} & \multirow[t]{3}{*}{20439.610} & \multirow[t]{3}{*}{22167.450} & 23016.087 & 22105.864 & 20889.808 & 22294.709 & 22570.546 & 22846.061 & 23121.253 & 23396.122 \\
\hline & $\operatorname{ARIMAx}(1,1,0)$ & & & & 23348.609 & 22176.424 & 22121.060 & 24171.280 & 26506.199 & 28715.645 & 30878.516 & 33013.792 \\
\hline & Combined & & & & 23182.348 & 22141.144 & 21505.434 & 23232.995 & 24538.373 & 25780.853 & 26999.885 & 28204.957 \\
\hline
\end{tabular}

These selected models are further put under diagnostic checking through $\mathrm{ACF}$ and $\mathrm{PACF}$ graphs of residuals (Fig. 1 and 2) and found that the residuals of selected models are free from significant correlations and used for forecasting coconut production up to 2020 .

The selected models are also validated for accuracy using last three years and observed that the actual and predicted values are in range and same can be observed from table 5 for the states of Andhra Pradesh, Karnataka, Kerala, West Bengal, Tamil Nadu and India as a whole respectively.

From the selected ARIMA Models the forecasted values obtained, it can be noted that production of coconut in Andhra Pradesh, Karnataka, Kerala, West Bengal, Tamil Nadu and India would be 1590.656, 5968.878, $8701.108,383.685,6113.942$ and 23396.122 million nuts respectively in 2020. Naveen et al., (2014) found that ARIMA $(1,1,1)$ model as an appropriate model to forecast the production of coconut for India and forecasted production for the year 2020 to be 15300.000 million nuts. The difference in the forecasted value between present study and study conducted by Naveen $e t$ $a l$., may be attributed to difference in period of data used and also recent data points were found to be high value outliers which is used in the present study. This might be the reason why the presented study forecasted value for coconut production for India is high compared to study conducted by Naveen et al., Similarly, from the selected ARIMAx Models the forecasted values obtained, it can be noted that production of coconut in Andhra Pradesh, Karnataka, Kerala, West Bengal, Tamil Nadu and India would be 2583.720, 6290.812, 7325.968, 355.583, 2957.986 and 33013.792 million nuts respectively in 2020 .

Compared to the year 2015, the forecasted figures indicate that production of coconut in the states of Andhra Pradesh, Karnataka and India as a whole would increase in future for both ARIMA and ARIMAx models considered. In case of Kerala and West Bengal the forecasted figures indicates that production would increase in future for the ARIMA models selected and would decrease for ARIMAx models 
considered. While Tamil Nadu figures indicate would decrease for ARIMA and drastically decrease for ARIMAx models considered.

\section{ARIMA, ARIMAx and combined model for production of coconut in India}

When the production of coconut is considered, from the table 4 it can be observed that combined forecasting performed better compared with ARIMA and ARIMAx in all most all cases considering the criteria of $R^{2}$, RMSE, MAE and MAPE except few cases as discussed below; In case of Andhra Pradesh combined forecast is best compared to both ARIMA and ARIMAx except having marginal increase in MAPE compared with ARIMA, it can be still noted that ARIMAx and Combined forecast bear same $\mathrm{R}^{2}$ values. In case of Karnataka when ARIMA, ARIMAx and Combined forecast are compared, each one have two better criteria compared with the other. In case of West Bengal combined is best compared with ARIMA except the criteria of MAPE which is high in case of combined forecasting. In India also Combined forecast is best than ARIMA and ARIMAx even though ARIMAx model have negligible increase in $\mathrm{R}^{2}$. The combined forecast values of the same can be found in table 5 .

Thus Compared to the year 2015, the forecasted figures indicate that production of coconut in the states of Andhra Pradesh, Karnataka and India as a whole would increase in future. In case of Kerala and West Bengal the forecasted figures indicates that production would increase in future for the ARIMA models considered. While Tamil Nadu figures indicates would decrease for both ARIMA and ARIMAx models considered. It is found that combined forecasting performed better compared with ARIMA and ARIMAx in all most all cases considering the criteria of $\mathrm{R}^{2}$, RMSE, MAE and MAPE. Among the three methods of modeling and forecasting ARIMAx models outperform ARIMA models and combined forecasting method yields better modeling and forecasting accuracy

\section{Acknowledgement}

The authors acknowledge and thank Department of Science and Technology for awarding Inspire fellowship for pursuing Doctoral Programme.

\section{References}

Anonymous. (Various issue). "Fertilizer statistics", Govt. of India.

Anonymous. 2018. Directorate of Economics and Statistics (DES). Department of Agriculture, Cooperation and Farmers Welfare, Ministry of Agriculture and Farmers Welfare. GOI.

Box, G.E.P. and Jenkins, G.M. 1976. Time Series Analysis: Forecasting and Control, Holden-Day, San Francisco.

Dhekale, B. S, et al., 2014. Modeling and forecasting of tea production in West Bengal. J Crop Weed. 10, pp. 94-103.

Hui, Z. and Yuhong, Y. 2004. Combining time series models for forecasting. International Journal of Forecasting, 20: 69-84.

Krishanan, M., Vasisht, A. K. and Sharma, B.M. 1991. Growth and instability in Kerala agriculture. Agril. Sitn. India, 46: 21-25.

Naveen, K., Rathod, S., Shukla, G. and Yogish, K.J. 2014. Forecasting of coconut production in India: A suitable time series model. International Journal of Agricultural Engineering, 7 (1): 190193.

\section{How to cite this article:}

Lakshmi Narsimhaiah, P.K. Sahu, Kanchan Sinha, Sh Herojit Singh, Soumik Dey and Pramit Pandit. 2019. Forecasting of Coconut Production in India: An approach with ARIMA, ARIMAx and Combined Forecast Techniques. Int.J.Curr.Microbiol.App.Sci. 8(11): 1710-1719. doi: https://doi.org/10.20546/ijcmas.2019.811.199 